\title{
Author Correction: Empirically observed learning rates for concentrating solar power and their responses to regime change
}

\author{
Johan Lilliestam, Mercè Labordena, Anthony Patt and Stefan Pfenninger
}

Correction to: Nature Energy https://doi.org/10.1038/nenergy.2017.94, published online 12 June 2017.

In the version of this Analysis originally published, the total learning rate for parabolic trough stations with 6-8 hours of thermal storage (Fig. 2b) was calculated to be $25 \%$. After publication, the authors found a code error that caused the learning curve fit function to believe that the first station in the dataset was marked as $1 \mathrm{GW}$ and not $0 \mathrm{GW}$. As a result, the estimated learning rates for the complete timespan were too high. The correct learning rates should be $2.7 \%$ for Fig. $2 \mathrm{a}$ and $6.8 \%$ for Fig. $2 \mathrm{~b}$ (instead of $5.2 \%$ and $25.2 \%$, respectively). These learning rate fit curves have been updated and the captions have been corrected. In Fig. 2a, the fit for 2011-2014 was unaffected. For consistency with Fig. 2a, a fit for 2011-2017 has been added to Fig. 2b, showing a learning rate of $17.5 \%\left(\mathrm{R}^{2}=0.337\right)$. The text has been modified in the abstract and the sections 'Observed investment cost development and learning rates', 'Policy regime impacts on cost development' and 'Conclusions' to reflect the quantitative changes to the learning rates. Supplementary Notes 1,3 and 4 and Supplementary Figs. 2, 6 and 7 and their captions have also been updated to reflect the new learning rates. In the caption of Supplementary Fig. 2b, " $(2008-2017$ learning rate $=0.21, \mathrm{R} 2=0.468)$ " has been changed to " $(2008-2017$ learning rate $=0.06, \mathrm{R} 2=0.513 ; 2011-2017$ learning rate $=0.079, \mathrm{R} 2=0.072)$ ". In the caption of Supplementary Fig. $6 \mathrm{~b}$, “ (2008-2017 learning rate $=0.289, \mathrm{R} 2=0.715)$ " has been changed to “(2008-2017 learning rate $=0.077, \mathrm{R} 2=0.631 ; 2011-2017$ learning rate $=0.225, \mathrm{R} 2=0.498)$ ”. In the caption of Supplementary Fig. 7, “(a) parabolic trough $(\mathrm{PT})$ stations with $<1$ hour thermal storage $(2011-2014$ learning rate $=0.297, \mathrm{R} 2=0.972$ (US $\$$ ) and learning rate $=0.27$, $\mathrm{R} 2=0.909(€)$ ); and (b) PT stations with 6-8 hours of thermal storage (2008-2017 learning rate $=0.252$, R2 $=0.621$ (US\$) and learning rate $=0.138, \mathrm{R} 2=0.502(€)$ )" has been changed to "(a) parabolic trough $(\mathrm{PT})$ stations with $<1$ hour thermal storage (2011-2014 learning rate $=0.297, \mathrm{R} 2=0.972$ (US $\$$ ) and 2011-2014 learning rate $=0.27, \mathrm{R} 2=0.909(€)$ ); and (b) PT stations with 6-8 hours of thermal storage (2011-2017 learning rate $=0.175, \mathrm{R} 2=0.337$ (US $\$$ ) and $2011-2017$ learning rate $=0.072, \mathrm{R} 2=0.149(€)$ )". The underlying data were correct as originally published and remain unchanged. The corrected figures are shown below.
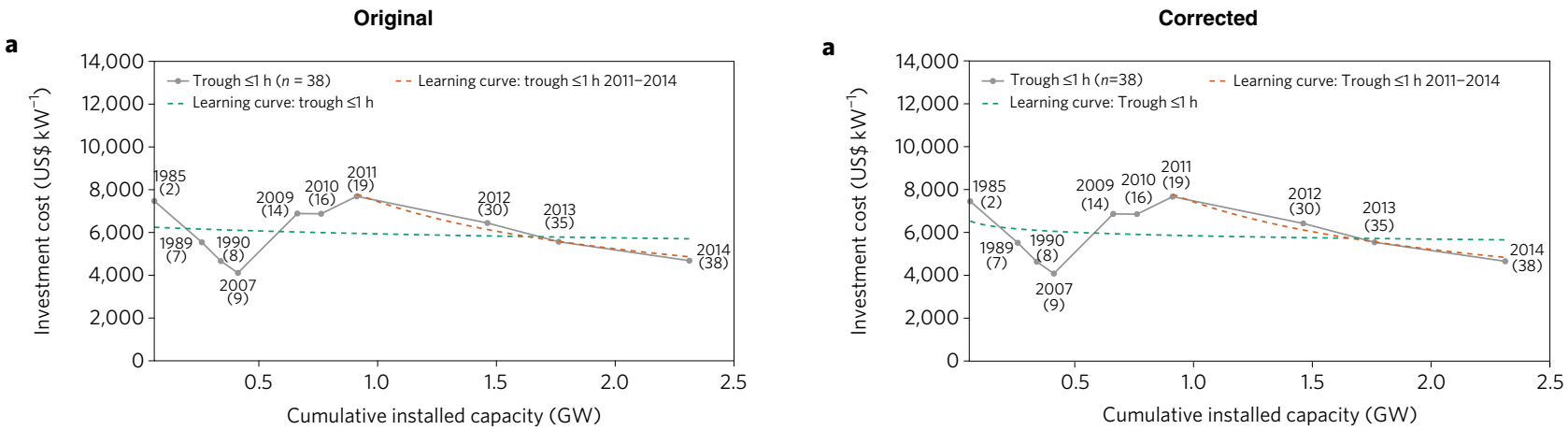

b

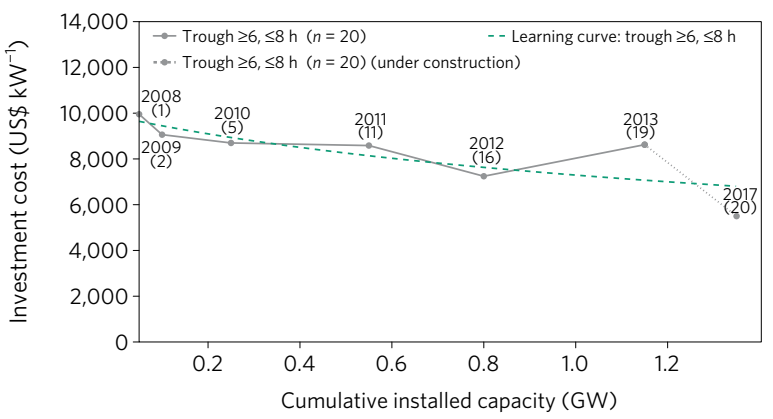

b

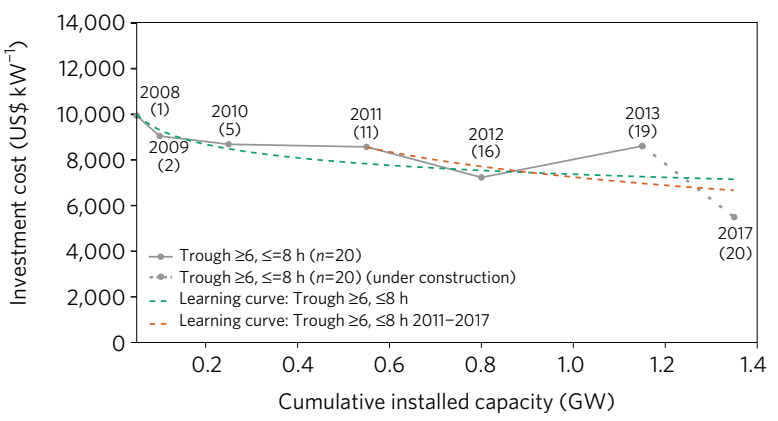

Fig. 2 | Original and Corrected. 


\section{NATURE ENERGY}

AMENDMENTS
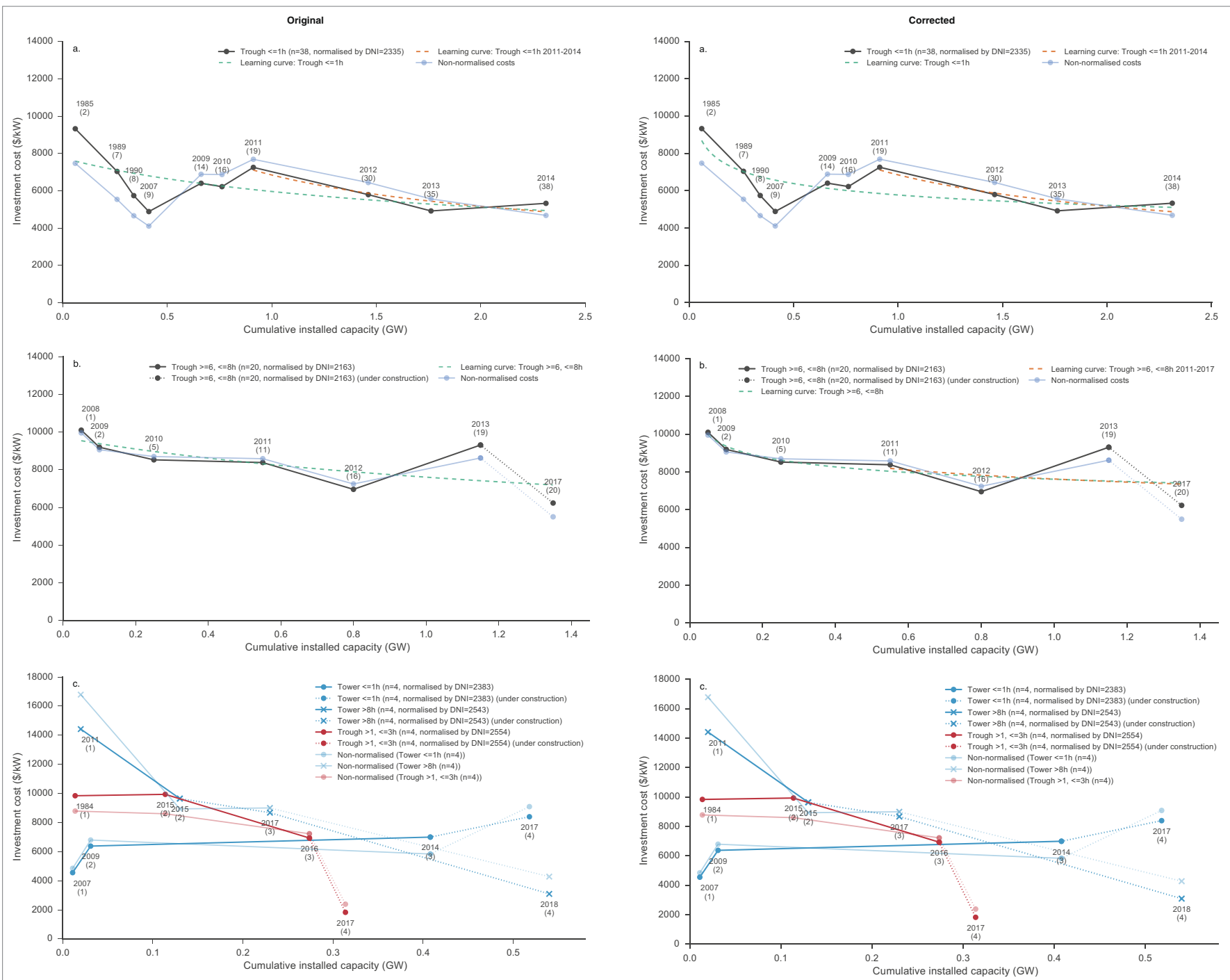

Supplementary Fig. 2 | Original and Corrected. 

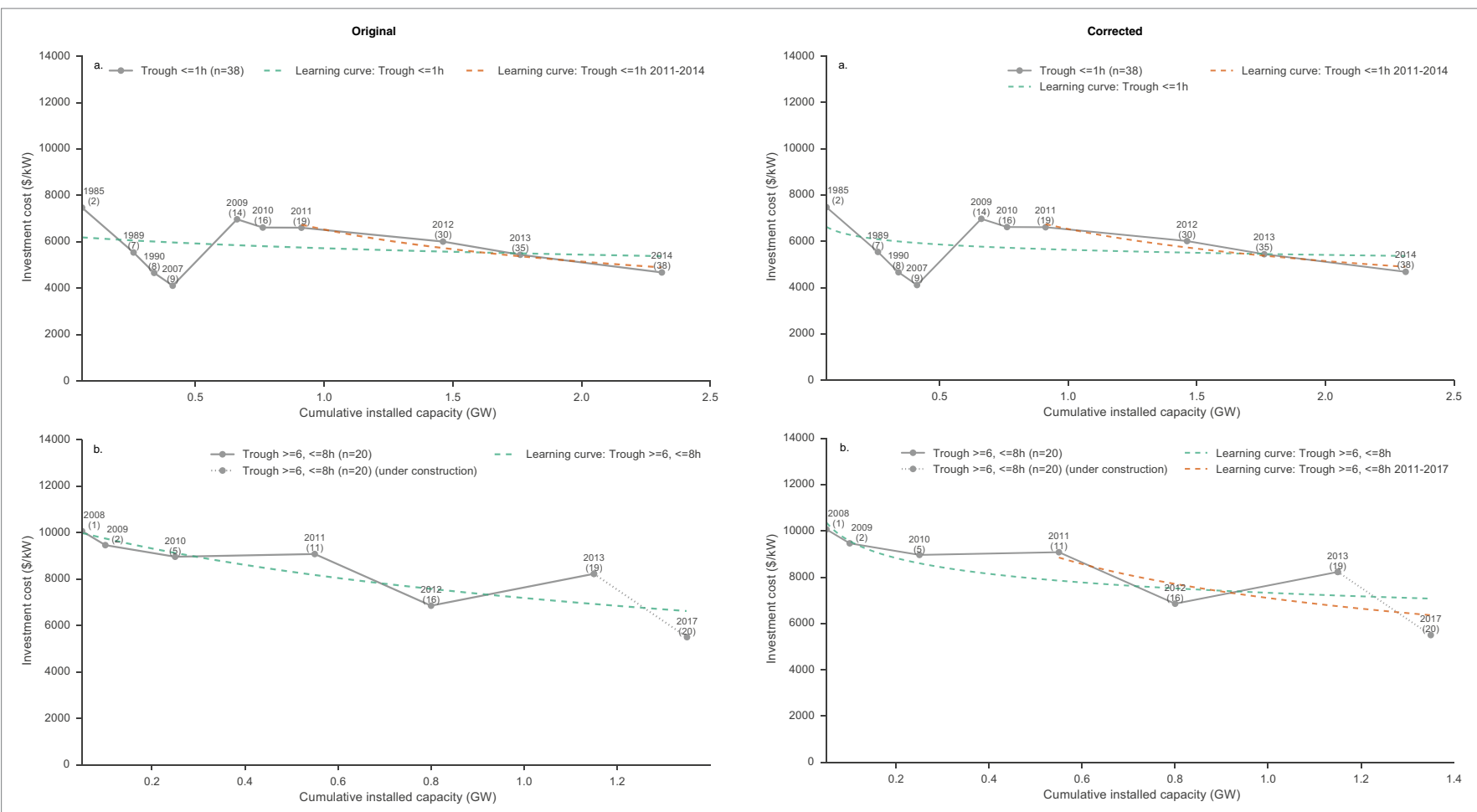

\section{Supplementary Fig. 6 | Original and Corrected.}
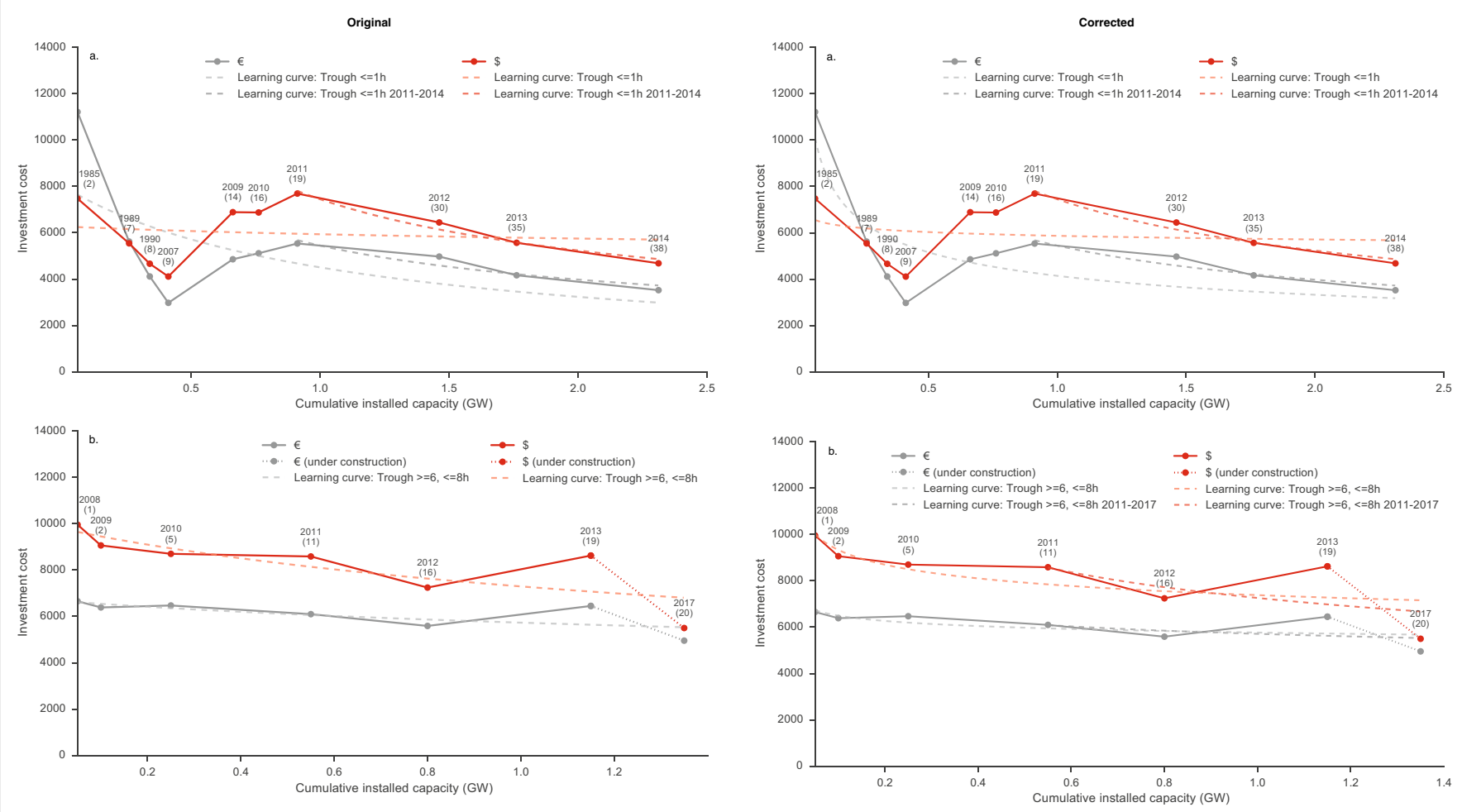

Supplementary Fig. 7 | Original and Corrected.

Published online: 22 March 2019

https://doi.org/10.1038/s41560-018-0315-9 